\title{
Palpable Masses Assessment Character Result in Standard Format
}

National Cancer Institute

\section{Source}

National Cancer Institute. Palpable Masses Assessment Character Result in Standard

Format. NCl Thesaurus. Code C119917.

The standard character or string for representation and reporting of palpable masses data. 